\title{
Interleukin-6 Selectively Enhances the Intracellular Calcium Response to NMDA in Developing CNS Neurons
}

\author{
Zhihua Qiu, Kathy L. Parsons, and Donna L. Gruol \\ Department of Neuropharmacology, The Scripps Research Institute, La Jolla, California 92037
}

Increasing evidence supports a role for cytokines as chemical signals in the CNS, either under normal conditions or in the pathologic state. CNS levels of the cytokine interleukin-6 (IL-6) are known to be elevated in several diseases associated with developmental disorders and may contribute to the pathological state. To investigate the potential role of IL- 6 in such disorders, neuronal effects of IL-6 were examined during development using an in vitro model system, cultured rat cerebellar granule neurons. The cultures were prepared from $8 \mathrm{~d}$ postnatal rat pups and exposed chronically to IL-6 $(5 \mathrm{ng} / \mathrm{ml})$ by addition to the culture medium. Neuronal effects of IL- 6 were assessed by a comparison of calcium signals produced in control and IL-6 treated neurons by the glutamate receptor agonists NMDA and domoate and by $\mathrm{K}^{+}$depolarization. IL- 6 treatment significantly enhanced the response to NMDA and altered the developmental pattern of NMDA sensitivity, whereas only minor changes were observed for the response to domoate and $\mathrm{K}^{+}$. Reducing extracellular calcium and depleting intracellular stores significantly decreased the amplitude of the response to NMDA in control and IL-6 treated neurons. However, the IL-6 treated neurons were significantly more sensitive to these treatments than control neurons. These results suggest that elevated levels of IL-6 can significantly alter CNS neuron development and response to excitatory transmitters, and that IL- 6 pretreatment selectively enhances the intracellular calcium responses to NMDA by altering the relative contribution of extracellular calcium influx and release of calcium from stores to the calcium signal.

[Key words: HIV, granule neurons, fura-2, cytokine, kainate receptor, growth factor, neurotropic factor]

Interleukin-6 is an important mediator of cellular communication both in physiological and pathological states (Hirano, 1992; Taga et al., 1992). Elevated levels of cytokines, including IL-6, have been found in the cerebrospinal fluid (CSF) and brains of children and adults infected with the human immunodeficiency virus (HIV) (Laurenzi et al., 1990; Gallo et al., 1991; Perrella et al., 1992; Tyor et al., 1992), and also in many other CNS diseases, such as Alzheimer's disease (Griffin et al., 1989), autoimmune disease (Hirohata and Miyamoto, 1990), and meningitis caused by bacteria (Waage et al., 1989) and virus (Frei et

\footnotetext{
Received Dec. 7, 1994; revised May 30, 1995; accepted June 1, 1995.

This work was supported by MH47680. We thank Floriska Chizer for secretarial help.

Correspondence should be addressed to Dr. Donna L. Gruol, Department of Neuropharmacology, CVN11, The Scripps Research Institute, 10666 North Torrey Pine Road, La Jolla, CA 92037.

Copyright (C) 1995 Society for Neuroscience $0270-6474 / 95 / 156688-12 \$ 05.00 / 0$
}

al., 1989). IL-6 receptors are known to be expressed in the CNS suggesting that they may play a role in CNS function (Schobitz et al., 1992; Sawada et al., 1993). IL-6 receptors share a common intracellular subunit with neuronal growth factor receptors (Ip et al., 1992; Stahl et al., 1994), and may influence neuronal development as well. However, little is known about the neuronal role of IL- 6 and the consequences of its elevation in the diseased states. For example, elevated levels of IL-6 in the CNS of HIV infected children may abnormally activate IL-6 receptors and affect CNS development. These children are known to have congenital and developmental problems (Brenneman et al., 1990; Belman, 1994). To assess IL-6's potential for CNS effects in the developing nervous system, wc have examined the acute and chronic effects of IL-6 exposure on an important neuronal function in the developing CNS, calcium signaling in response to stimulation of glutamate receptors. Calcium is an important intracellular messenger known to control many aspects of neuronal function including enzyme activity (e.g., kinases and phosphatases), gene expression, synapse function, and neurotransmitter release. Glutamate is the main excitatory transmitter in the CNS and is known to play an important role in neuronal development (McDonald et al., 1990b; Komuro and Rakic, 1993). Therefore, IL-6 induced changes in calcium signaling could profoundly affect neuronal function in the developing nervous system.

IL-6's effects were examined in cultured cerebellar granule neurons grown in relative isolation from other cell types, such as microglia or astrocytes, which could also respond to the cytokine. Granule neurons express NMDA, AMPA, and kainate subtypes of glutamate receptors (Monaghan et al., 1989; Traynelis and Cull-Candy, 1991). Calcium signaling elicited by activation of NMDA and kainate receptors was assessed using selective agonists, NMDA and domoate, respectively. Activation of these receptors increases intracellular calcium via several pathways: (1) calcium influx through receptor-gated channels, (2) calcium influx through voltage sensitive calcium channels activated by membrane depolarization, and (3) release of calcium from intracellular calcium stores. $\mathrm{K}^{+}$depolarization was examined as well, which increases intracellular calcium via voltage-sensitive calcium channels and calcium release from intracellular calcium stores. IL- 6 treatment substantially enhanced the calcium signals produced by NMDA stimulation but not by domoate stimulation or $\mathrm{K}^{+}$depolarization. In addition, the developmental profile of NMDA responsivity was changed by IL- 6 treatment. These results suggest that elevated levels of IL-6 could significantly influence NMDA receptor mediated processes and neuronal development in the CNS. 


\section{Materials and Methods}

Cell culture. Cerebellar granule cells from $8 \mathrm{~d}$ old postnatal SpragueDawley rats were isolated by a standard enzyme treatment protocol based on the methods of Trenkner (1991). Briefly, ccrebella werc dissociated in calcium-free saline with trypsin and DNase, then plated on MATRIGEL (Collaborative Biomedical Products, Bedford, MA) coated coverglasses $\left(\sim 10^{6} \mathrm{cell} / \mathrm{ml}\right)$. The neurons were grown in DMEM/F12 plus $10 \%$ horse serum supplemented with $30 \mathrm{~mm}$ glucose, $2 \mathrm{~mm}$ glutamine, $25 \mathrm{mM} \mathrm{KCl}$, and $25 \mu \mathrm{M}$ penicillin-streptomycin; $0.5 \mathrm{ml}$ of medium without serum was added every $7 \mathrm{~d}$. Contaminating astrocytes were minimized by treatment with FUDR $(20 \mu \mathrm{g} / \mathrm{ml})$ on the first and fourth days after plating. The cultures survived for about $20 \mathrm{~d}$ in a standard $\mathrm{CO}_{2}$ incubator.

IL-6, $5 \mathrm{ng} / \mathrm{ml}(500 \mathrm{U} / \mathrm{ml})$, was added to the cell cultures $1 \mathrm{~d}$ after plating and supplemented again at day 4,7 , and 11. Control cultures consisted of sister cultures which were not treated with IL-6. The neurons were observed throughout the first 2 weeks in culture. The IL-6 containing medium was replaced by physiological saline before measurements were made.

Intracellular calcium measurement. Intracellular calcium was determined for individual cells using standard microscopic fura-2 digital imaging (Grynkiewicz et al., 1985) and previously published methods (Holliday and Gruol, 1993). Granule neurons were loaded with $3 \mu \mathrm{M}$ fura-2/AM for $30 \mathrm{~min}$, then, for an additional $45 \mathrm{~min}$, incubated in dyefree saline solution at room temperature to allow cleavage of acetoxymethyl (AM) ester. The coverglass was then mounted in a chamber attached to the stage of an inverted microscope equipped for fura-2 video images. Live video imagines of selected microscopic fields were recorded with SIT- 66 video camera (DAGE-MTI) and digitized by computer. Ratio images were formed by a pixel-by-pixel division of the 340 $\mathrm{nm}$ excited image/the $380 \mathrm{~nm}$ excited image. Real time digitized display, image acquisition, and calcium measurements were made with MCD imaging software (Imaging Research Inc.). The somata of approximately $5-10$ cells in each microscopic field were individually measured. Intracellular calcium levels were estimated by converting fluorescent ratios $(340 \mathrm{~nm} / 380 \mathrm{~nm})$ to intracellular calcium concentration using the following formula: $\left.\left[\mathrm{Ca}^{2+}\right]_{i}=K_{d}\left(R-R_{\min }\right) / R-R_{\max }\right)^{*} F_{o} / F_{s}$, where $R$ is the ratio value, $R_{\min }$ is the ratio for a calcium free solution, $R_{\max }$ is the ratio for a saturated calcium solution, $K_{d}$ is 135 (the dissociate constant for fura-2), $F_{o}$ is the intensity of a calcium free solution at 380 $\mathrm{nm}$, and $F_{s}$ is the intensity of a saturated calcium solution at $380 \mathrm{~nm}$. Calibration was done using fura salt $(100 \mu \mathrm{M})$ in solutions of known calcium concentration. All experiments were performed at room temperature $\left(23^{\circ} \mathrm{C}\right)$

Drug application. Cells were stimulated with micropressure application of cither NMDA $(200 \mu \mathrm{M})$ or domoate $(20 \mu \mathrm{M})$, selcetive agonists at the NMDA and kainate subtypes of glutamate receptors respectively, and $\mathrm{K}^{+}\left(150 \mathrm{mM} ; \mathrm{K}^{+}\right.$substituted for $\mathrm{Na}^{+}$in physiological saline) which causes membrane depolarization to $\sim 0 \mathrm{mV}$. The agonists were dissolved in bath saline and applied by a brief ( $1 \mathrm{sec})$ micropressure pulse from drug pipettes (1-3 $\mu \mathrm{m}$ tip) placed under visual control near target neurons. $\mathrm{K}^{+}$was applied in the same manner. A dye (fast green, $0.05 \mathrm{mg} \%$ ) was included in the agonist solution to monitor neuronal exposure and showed that the agonist or $\mathrm{K}^{+}$was rapidly distributed over an area sufficient to expose the target neurons. In control experiments, the dye had no effect by itself nor did it influence the response to NMDA.

Video images were collected at $3 \mathrm{sec}$ intervals for at least $12 \mathrm{sec}$ before stimulation and $100 \mathrm{sec}$ after stimulation. To ensure that the peak of the response was detected, the first collection after stimulation was made within $1 \mathrm{sec}$ of stimulation, with subsequent collections occurring at $3 \mathrm{sec}$ intervals. Control studies using shorter collection intervals confirmed that this collection paradigm was adequate to resolve response parameters. The time course of neuronal exposure to agonists was estimated by a series of control experiments on granule neurons using $\mathrm{K}^{+}$ (150 mM; $\mathrm{K}^{+}$substituted for $\mathrm{Na}^{+}$in physiological saline) depolarization. In electrophysiological studies, a 1 sec application of the high $\mathrm{K}^{+}$saline depolarized the membrane potential to $0 \mathrm{mV}$, as did bath application of the high $\mathrm{K}^{+}$saline, indicating that a $1 \mathrm{sec}$ application period was sufficient to expose the neuronal surface to the full agonist concentration in the pipette. The maximum depolarization to $\mathrm{K}^{+}$occurred $1.2 \pm 0.07$ seconds $(n=5)$ after stimulation and was maintained for $0.7 \pm 0.04$ $\sec (n=5)$, indicating that the exposure period to the full agonist concentration was rather brief, but of sufficient duration to be detected by the first collection interval $(1 \mathrm{sec})$ if calcium changes paralleled membrane potential changes. The time for clearance of the agonist was estimated by the visual clearance of the dye (included in the agonist pipette) from the neuron, which took about $15 \mathrm{sec}$.

For NMDA stimulation, the cell bath and agonist solutions were magnesium-free physiological saline containing $5 \mu \mathrm{M}$ glycine. For the stimulations of domoate and $\mathrm{K}^{+}$depolarization, the bath contained normal physiological saline. In some experiments, the neurons were exposed to antagonists or other drugs by bath exchange. These drugs included MK801, ethylene glyco-bis ( $\beta$-aminoethyl ether) $N, N, N^{\prime}, N^{\prime}$-tetraacetic acid (EGTA), dantrolene, caffeine, and 2,5-di(tert-butyl)1,4-benzohydroquinone (DTBHQ).

Drugs. Human recombinant interleukin-6 (IL-6) (Boehringer Mannheim, Germany) was dissolved in physiological saline at $100,000 \mathrm{U} / \mathrm{ml}$ as stock solution and stored at $-20^{\circ} \mathrm{C}$ for no more than 3 weeks. NMDA and domoate were obtained from Tocris Neuramin, England, and stored as stock solutions at concentrations of $50 \mathrm{~mm}$ and $1 \mathrm{~mm}$, respectively. MK-801 (Sigma Chemical CO. St. Louis, MO) was dissolved in dimethyl sulfoxide (DMSO) at a concentration of $10 \mathrm{~mm}$ as a stock solution. The final concentration of DMSO was not more than $0.05 \%$ in the cell bath solution. In control experiments DMSO had no effects by itself. EGTA (Sigma Chemical Co., St. Louis, MO) was applied at a concentration of $1 \mathrm{~mm}$ to tritriate the extracellular calcium. Caffeine and dantrolene were purchased from Sigma Chemical Co. (St. Louis, MO). DTBHQ was purchased from Aldrich Chemical Co. (Milwaukee, WI).

Data analysis. Intracellular calcium responses were quantified by measurement of peak amplitude. Resting calcium levels were subtracted from all peak amplitude values on an individual cell basis. Each protocol consists of two or three culture sets of developing granule neurons, in which 5-15 granule neuronal somata in each field were measured. Data from several cultures were pooled for statistical analyses. Values are expressed as mean \pm SEM. Statistical significance was determined by one-way analysis of variance (ANOVA) followed by the Fisher posthoc test for multiple comparisons. $p<0.05$ was considered indicative of a statistically significant difference.

\section{Results}

\section{Granule neuron development in vitro}

Granule neurons obtained from $8 \mathrm{~d}$ old rat pup cerebellum and plated on glass coverslips coated with MATRIGEL show distinctive developmental changes during the culture period, thus providing an accessible developmental model. The morphological changes during development are shown in Figure 1. At the time of plating, the granule neurons generally have a rounded shape. During the first day in culture, they attach to the substrate and start migrating. Gradually, clusters of cells form, and by the fifth day in culture, prominent fiber tracks are observed. The fiber tracks and clusters increase in size with culture age before 8 DIV, after which they appear relatively stable. Neurons in IL-6 treated cultures showed a similar developmental pattern.

\section{NMDA induced intracellular calcium signals}

The physiological properties of granule neurons including the sensitivity to NMDA, a selective agonist for the NMDA subtype of glutamate receptor, are known to change during development (Farrant et al., 1994; Hockberger et al., 1994; Monyer et al., 1994). To determine if IL-6 could influence these properties, we examined the calcium response to stimulation with NMDA. IL-6 treatment significantly enhanced the calcium signals produced by NMDA stimulation in the cultured granule neurons. This effect was observed at all culture ages tested. Figure $2 A-C$ shows typical intracellular calcium recordings from the cerebellar granule neurons in control cultures and in cultures chronically exposure to IL-6 $(500 \mathrm{U} / \mathrm{ml})$ for 6,8 , and $12 \mathrm{~d}$ prior to testing. In both control and IL- 6 treated neurons, the calcium response evoked by NMDA was characterized by a rapid initial peak and slower recovery phase. The amplitudes of the calcium signals were significantly larger in IL-6 treated neurons compared to 

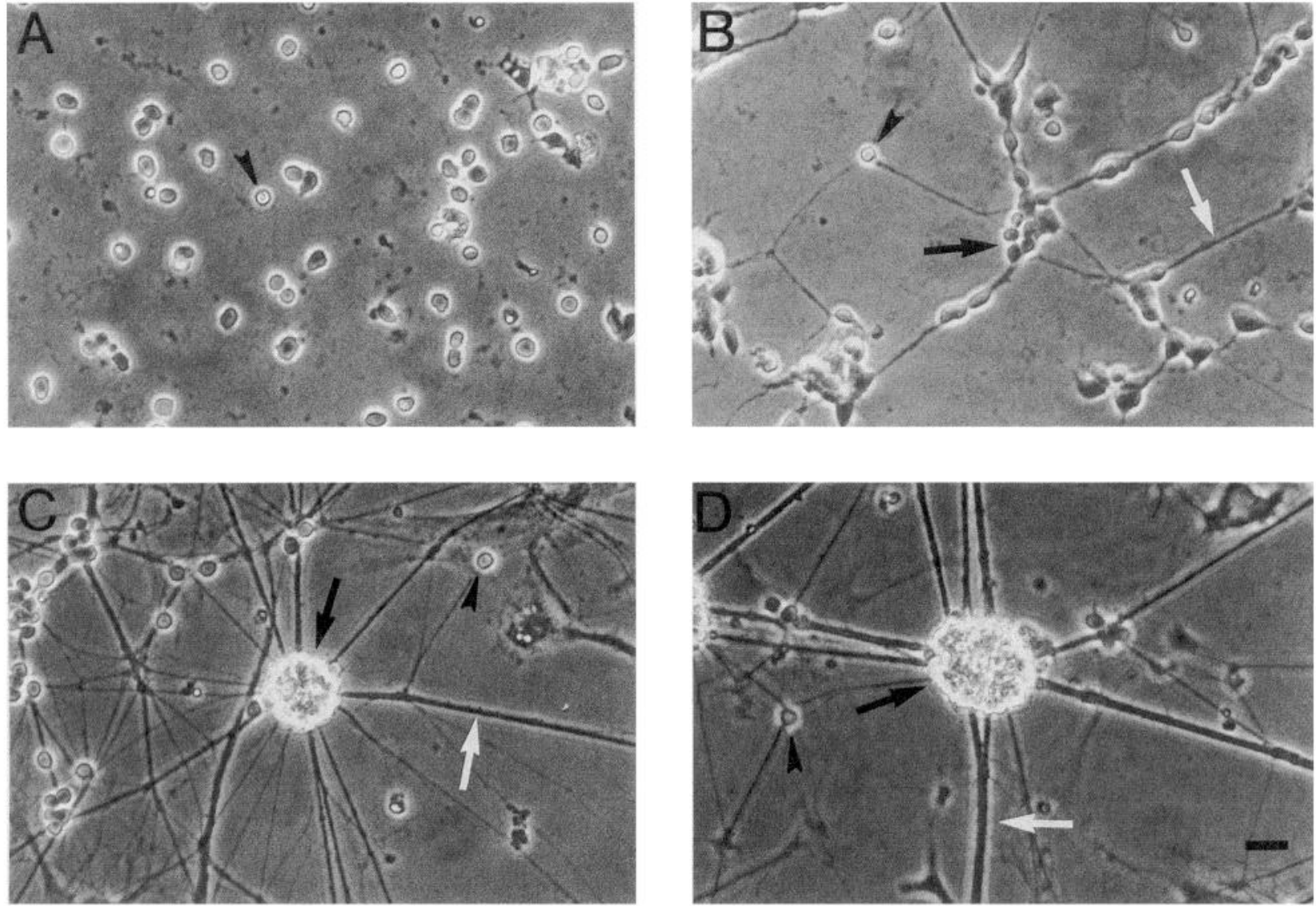

Figure 1. The morphological changes of cultured granule neurons during neuronal development in culture as seen in phase contrast micrographs. $A-D$ are granule neurons in control cultures at different culture ages: $0,1,5$, and 8 DIV. Clusters of cells formed by groups of migrating neurons are indicated by the black arrow in $A, B$, and $D$ and single neurons indicated by a black arrowhead in $A-D$. By the fifth day in culture, prominent fiber tracks are observed, as indicated by the white arrow in $C$ and $D$. Scale bar, $20 \mu \mathrm{m}$.

controls at all culture ages. Moreover, the calcium responses to NMDA in control neurons reached a peak at 6 DIV and then declined with development, whereas in IL-6 treated neurons the signal remained elevated throughout neuronal development. Mean values for the population of neurons studied are shown in Figure $2 \mathrm{D}$. In control experiments, denatured (heating to $100^{\circ} \mathrm{C}$ for $30 \mathrm{~min}$ ) IL-6 did not influence the response to NMDA in the granule neurons (not shown).

The effect of MK-801, a NMDA receptor antagonist, was tested to determine if the intracellular calcium responses to NMDA in both control and IL- 6 treated neurons were induced by NMDA receptor activation. After the neurons were incubated in saline containing the noncompetitive NMDA receptor antagonist MK- $801(10 \mu \mathrm{M})$ for $5 \mathrm{~min}$, NMDA did not induce a measurable increase of the intracellular calcium in either control (Fig. $3 A$ ) or IL-6 treated neurons (Fig. $3 B$ ). These results indicate that the intracellular calcium changes produced by NMDA stimulation were specifically induced by NMDA receptor activation in both control and IL- 6 treated neurons.

In addition to its effects on the NMDA response, IL-6 also altered resting calcium levels. Resting calcium levels varied during development but were consistently higher in the IL- 6 treated neurons. For example the resting calcium levels were $43 \pm 2$ and $49 \pm 2$ in control $(n=168)$ and IL-6 treated neurons $(n=$ $180)$ respectively $(p<0.05)$ at 8 DIV.

\section{$K^{+}$induced intracellular calcium signals}

Activation of NMDA receptors causes a membrane depolarization that could activate voltage sensitive calcium channels resulting in a calcium signal. An enhancement of this signal by IL-6 treatment could contribute to the larger response to NMDA in the IL- 6 treated neurons. To test this possibility, the effect of IL-6 treatment on calcium signals elicited by $\mathrm{K}^{+}$depolarization was investigated. $\mathrm{K}^{+}$depolarization activates voltage-sensitive calcium channels independent of NMDA receptor activation. IL6 treatment had no effect on the $\mathrm{K}^{+}$evoked calcium signal or the developmental changes in the amplitude of this signal. Representative recordings are shown in Figure $4 A-C$ and mean values in Figure $4 D$.

\section{Domoate induced intracellular calcium signals}

Granule neurons express multiple subtypes of glutamate receptors. Therefore, it was of interest to determine if responses evoked by another glutamate receptor agonist was affected by the IL-6 treatment. We examined the intracellular calcium responses to domoate, a kainate receptor agonist, at different developmental ages. Domoate stimulation produced an increase in intracellular calcium characterized by an initial peak and slow recovery phase in both control and IL-6 treated cultures. Representative responses are shown in Figure $5 A-C$ at different culture ages. IL- 6 treatment did not consistently alter the response 
A

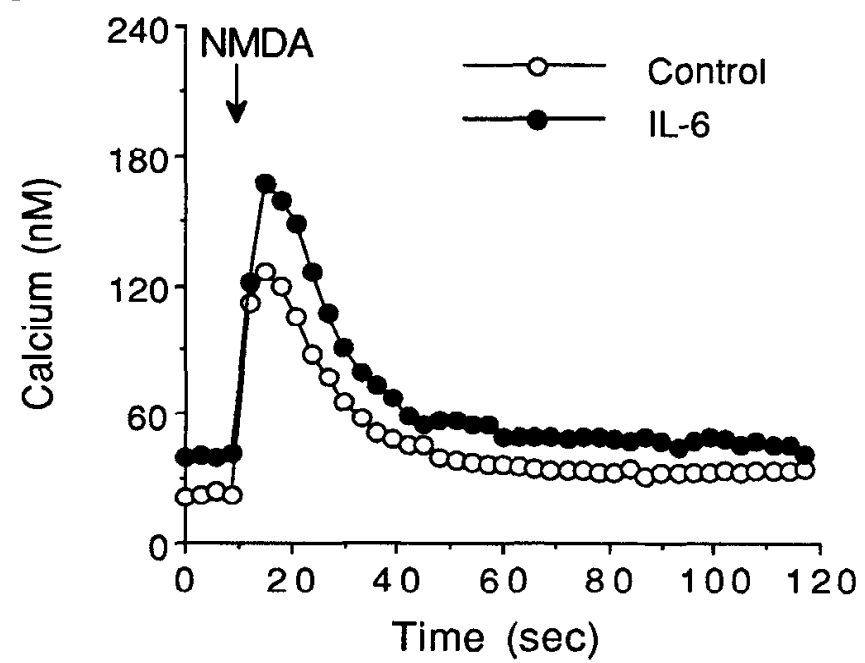

C

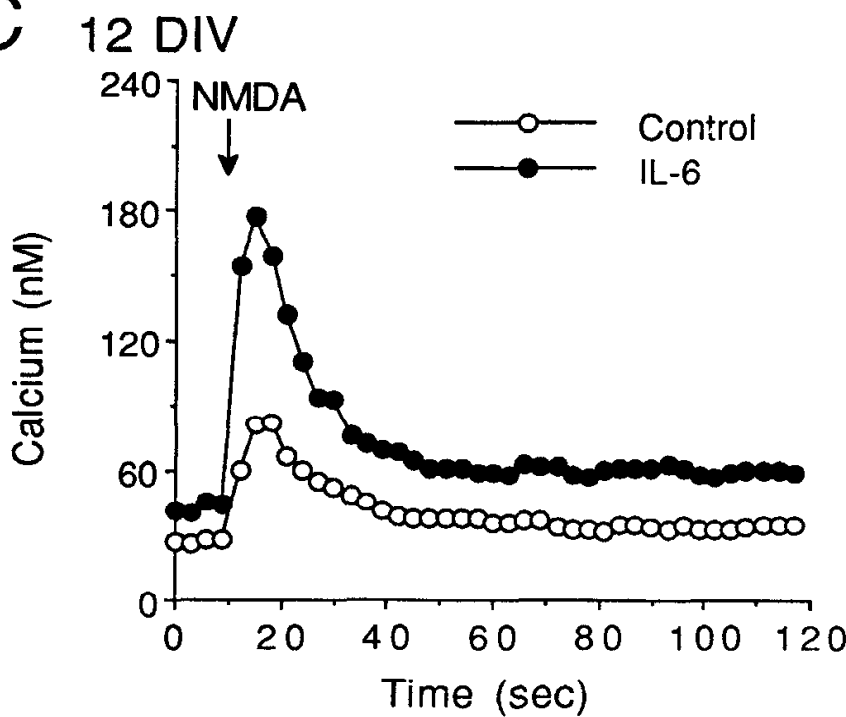

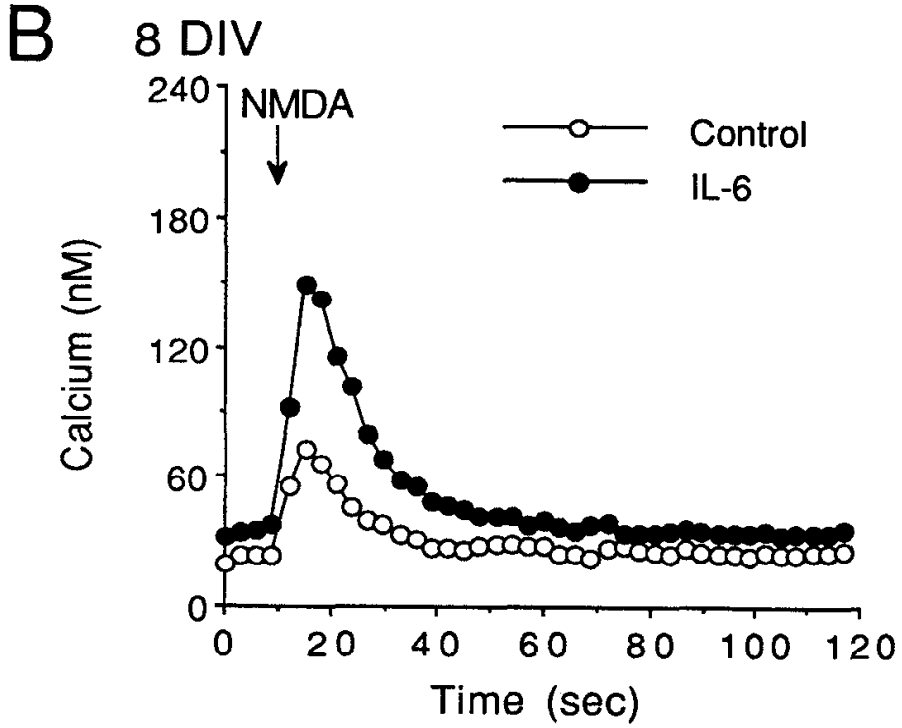

D

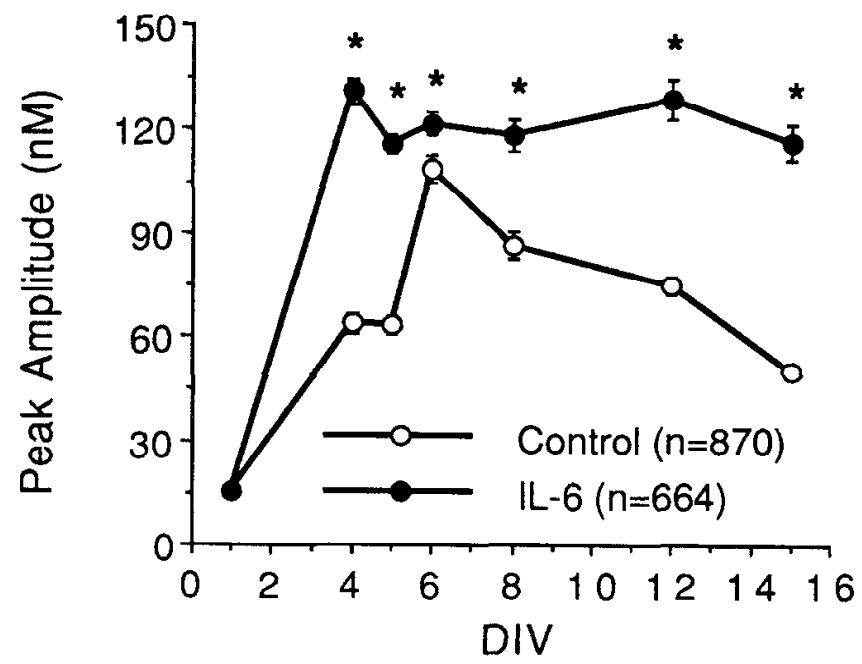

Figure 2. Intracellular calcium signals evoked in cultured cerebellar granule neurons by NMDA during neuronal development. $A-C$ show representative recordings of intracellular calcium signals evoked by brief $(1 \mathrm{sec})$ application of NMDA (applied at the arrow) from a micropipette in both control (open circle) and IL-6 treated neurons (solid circle) during development. $D$ shows the time-dependent change of intracellular calcium response to NMDA during development. Each data point is an average (mean \pm SEM) for cells measured within a particular age group for control neurons (open circle) and IL-6 treated neurons (solid circle). Data points marked with a star indicate a significant $(p<0.05)$ difference between control and IL-6 treated neurons in this and subsequent figures. $n$ is the total number of cells studied. IL- 6 treatment significantly enhanced the response to NMDA.

to domoate. Mean values are shown in Figure $5 D$. In both control and IL- 6 treated neurons, the intracellular calcium responses to domoate peaked at 6 DIV and then declined with further neuronal maturation (Fig. 5), a developmental pattern similar to that for the intracellular calcium responses to NMDA in control neurons (Fig. 2).

The acute effects of IL-6 treatment cultured cerebellar granule neurons

To test if acute treatment with IL-6 could produce effects similar to chronic treatment, acute IL- 6 was applied by micropressure or bath application of a standard dose of IL-6 $(500 \mathrm{U} / \mathrm{ml})$ to neurons in control cultures and cultures chronically treated with same concentration of IL- 6 for $4 \mathrm{~d}$. In addition, in control cultures acutely treated with IL-6 the response to NMDA stimula- tion was monitored during acute bath addition of IL-6. Results are shown in Figure 6. There was no measurable intracellular calcium response to IL- 6 stimulation when IL- 6 was applied by micropressure pulse (Fig. 6A) to control and IL-6 treated neurons. Acute IL -6 via bath application did not significantly affect the intracellular calcium responses of control granule neurons to NMDA (Fig. 6B,C). These results indicated that acute IL-6 does not induce the same effects as chronic IL- 6 on cerebellar granule neurons.

\section{Influence of lowing extracellular calcium on NMDA-induced} intracellular calcium responses

Extracellular calcium influxing through NMDA gated calcium channels contributes to the intracellular calcium signal in response to NMDA stimulation in cerebellar granule neurons. To 

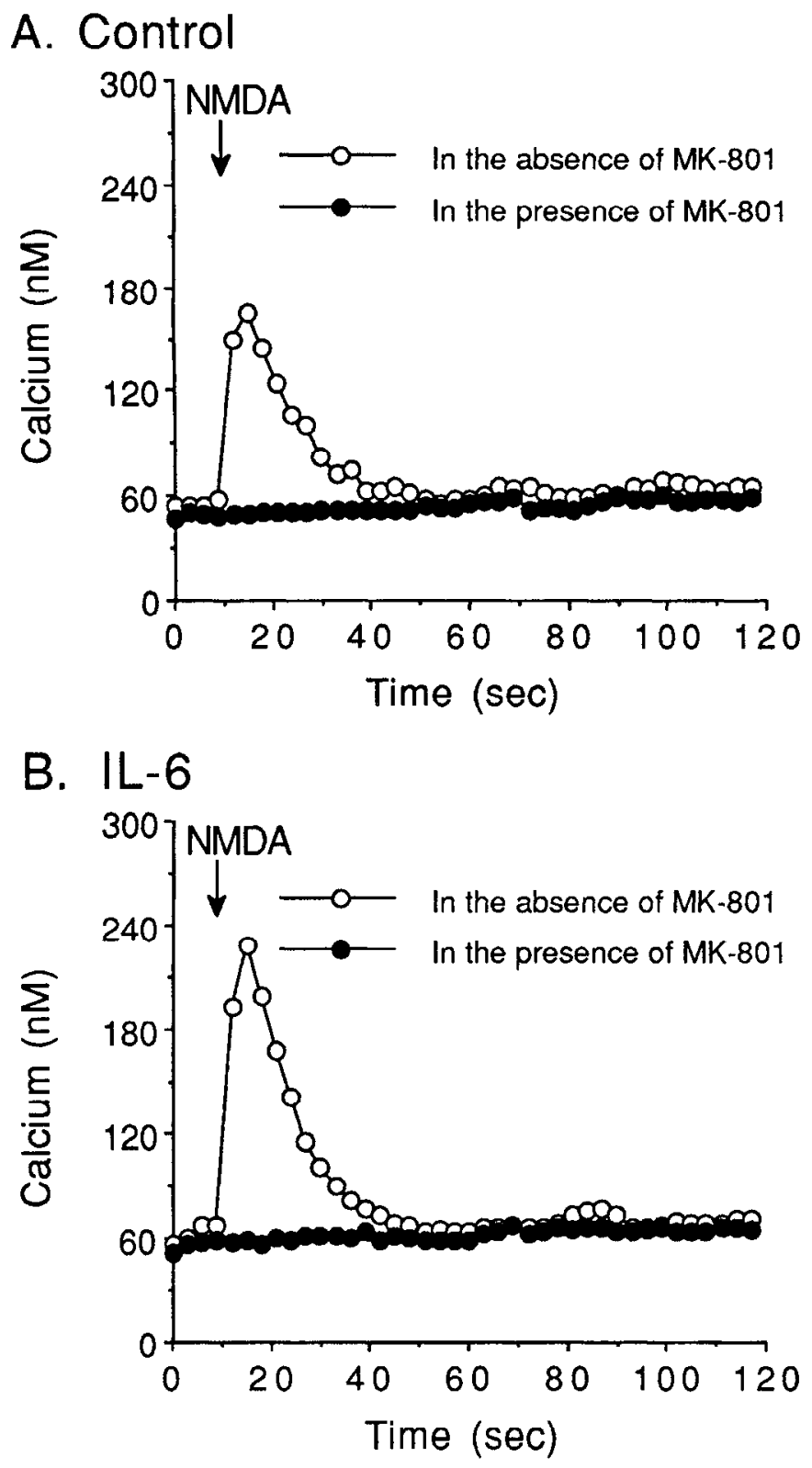

Figure 3. Effccts of NMDA receptor antagonist MK-801 on the intracellular calcium response to NMDA stimulation. Neurons at 5 DIV were incubated in saline containing the noncompetitive NMDA receptor antagonist MK-801 $(10 \mu \mathrm{M})$ for $5 \mathrm{~min}$, before the application of NMDA (MK-801 was also included in the micropipette). NMDA was applied at the arrow. NMDA did not induce any measurable increase of the intracellular calcium in control neurons $(A)$ and IL-6 treated neurons $(B)$ in the presence of MK-801 (solid circle) compared to the intracellular calcium response to NMDA in the absence of MK-801 (open circle).

test if the enhanced intracellular calcium responses to NMDA in IL-6 treated neurons were due to an increase dependence on extracellular calcium influx, we examined the effect of lowing extracellular calcium on the response to NMDA at different developmental ages. Results are summarized in Figure 7.

In 5 DIV neurons, lowering extracellular calcium from 2.2 to $0.22 \mathrm{mM}$ reduced the response to NMDA in both control and IL-6 treated neurons. Similar effects were observed in the 8 and 12 DIV neurons. However at the older ages ( 8 and 12 DIV), lowering extracellular calcium from $2.2 \mathrm{~mm}$ to $0.22 \mathrm{~mm}$ had a much greater effect on the intracellular calcium response to NMDA in IL-6 treated neurons (Fig. $7 B$ ), almost completely eliminating the difference between control and IL-6 treated neurons. These result indicate that extracellular calcium is an inportant component of the NMDA response and contributes to the enhanced response in IL- 6 treated cultures at older ages $(8$ and 12 DIV). The NMDA-induced intracellular calcium responses were eliminated in both control and IL- 6 treated neurons when extracellular calcium was reduced to nominally calcium free by EGTA titration (Fig. 7C).

\section{Involvement of intracellular calcium stores in NMDA-induced intracellular calcium responses}

Calcium induced calcium release (CICR) from intracellular calcium stores located on the endoplasmic reticulum could also contribute to NMDA induced intracellular calcium response in the granule neurons. Such release could be trigged by extracellular calcium influx via either NMDA-gated channels or voltagesensitive calcium channels activated by membrane depolarization. The increase in intracellular calcium could activate the ryanodine receptor causing release of calcium from stores controlled by that receptor. Changes in intracellular calcium could also modulate release of calcium from stores controlled by the inositol trisphosphate receptor $\left(\mathrm{IP}_{3}\right)$, if such release occurs under resting conditions. NMDA did not elicit a calcium signal in the absence of extracellular calcium indicating that NMDA does not significantly stimulate production of $\mathrm{IP}_{3}$ and calcium release via the IP receptor in the granule neurons. To examine the role of intracellular stores in NMDA-induced intracellular calcium responses, both control and IL-6 treated rat granule neurons at 5 , 8, and 12 DIV were tested under the following conditions: (1) in the presence of $20 \mathrm{~mm}$ caffeine, which depletes intracellular calcium stores (Tsien and Tsien, 1990; Miller, 1991); (2) in the presence of $10 \mu \mathrm{M}$ dantrolene, an antagonist of the ryanodine receptor (Tsien and Tsien, 1990; Miller, 1991; Charles et al., 1993); and (3) in the presence of $10 \mu \mathrm{M}$ DTBHQ, which depletcs the intracellular calcium stores by inhibiting the calcium ATPase of the endoplasmic reticulum that is responsible for sequestering calcium into these stores (Kass et al., 1989; Tsien and Tsien, 1990; Holliday et al., 1991).

Figure 8 shows the effect of caffeine on NMDA-induced intracellular calcium responses of cerebellar granule neurons in control and IL-6 treated neurons at different culture ages; 20 mM caffeine reduced the response to NMDA in both control and IL-6 treated neurons but the effects were much larger for the IL-6 treated neurons than for controls (Fig. 8). At 5 DIV caffeine treatment abolished the difference between control and IL-6 treated neurons. At older ages ( 8 and 12 DIV) the difference between control and IL- 6 treated neurons was greatly reduced by caffeine but not abolished. These results suggested that the intracellular calcium stores contribute not only to the intracellular calcium responses to NMD $\Lambda$ in both control and IL- 6 treated neurons but also to the enhanced intracellular calcium response to NMDA in the neurons chronically treated with IL-6.

The effects of dantrolene on control and IL-6 treated neurons are shown in Figure 9A. Dantrolene reduced the calcium responses to NMDA stimulation in IL-6 treated but not control neurons at 5 DIV and in both IL- 6 treated and control neurons at 8 and 12 DIV. Thus, IL- 6 treated neurons expressed sensitivity to dantrolene earlier in development than control neurons. At 5 DIV dantrolene abolished the difference in magnitude of the NMDA response between control and IL-6 treated neurons, 

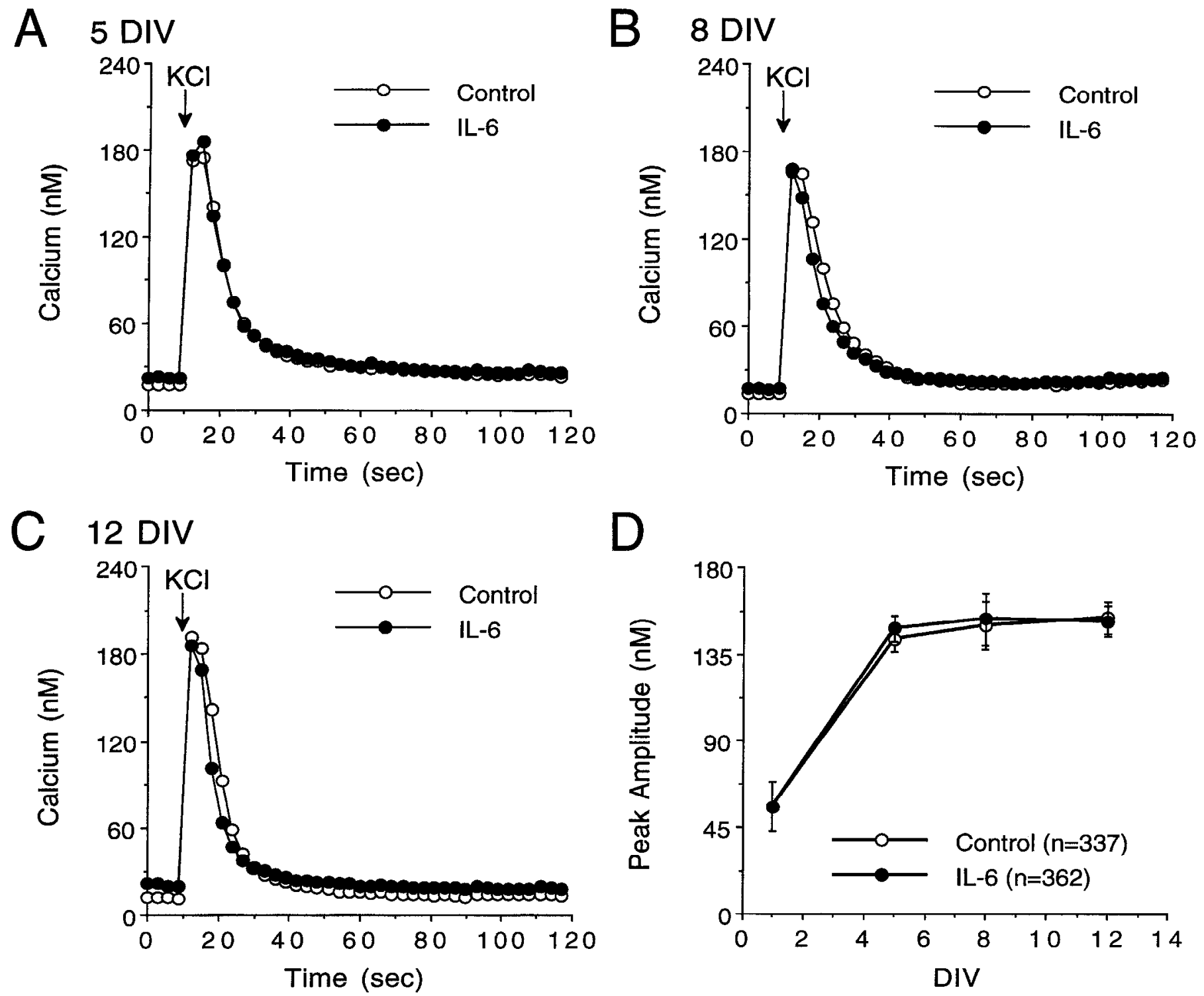

Figure 4. Intracellular calcium signals evoked in cultured cerebellar granule neurons by $\mathrm{K}^{+}$depolarization during neuronal development. $A-C$ show representative recordings of intracellular calcium signals evoked by brief $(1 \mathrm{sec})$ application of $\mathrm{K}^{+}$(applied at the arrow) from a micropipette in both control (open circle) and IL-6 treated neurons (solid circle) during development. $D$ shows the time-dependent change of intracellular calcium response to $\mathrm{K}^{+}$depolarization during development. Each data point is an average (mean + SEM) for cells measured within a particular age group for control neurons (open circle) and IL-6 treated neurons (solid circle). $n$ is the total number of cells studied. The response to $\mathrm{K}^{+}$depolarization was not significantly altered by IL- 6 treatment during development.

whereas at older ages the difference was greatly reduced but not abolished, results similar to that observed with caffeine. These results show that the neurons were more sensitive to dantrolene at older ages ( 8 and 12 DIV) than at 5 DIV and that the IL-6 treated neurons were more sensitive to dantrolene than control neurons at all agcs. In addition, the results indicate that increased calcium release through dantrolene-sensitive intracellular calcium stores contributes to the enhanced calcium signals of IL-6 treated neurons.

Figure $9 B$ shows that the effects of DTBHQ on the enhancement of the calcium responses to NMDA stimulation induced by IL-6 pretreatment during neuron development. DTBHQ reduced the calcium response to NMDA stimulation in both control and IL-6 treated neurons during neuronal development (Fig. $9 B)$. In addition, the neurons were more sensitive to DTBHQ at 5 DIV than at 8 DIV and the IL-6 treated neurons were more sensitive to DTBHQ than the control neurons at 8 and 12 DIV. These results indicate that the DTBHQ-sensitive intracellular calcium stores contribute to the increased calcium signals of IL-6 treated neurons at 8 and 12 DIV, consistent with results from studies with caffeine and dantrolene treatment.

Caffeine and DTBHQ treatment also altered resting calcium levels. Resting calcium level was increased by caffeine and DTBHQ in both control and IL-6 treated neurons. For example, mean resting calcium levels at 8 DIV were increased from 43 $\pm 2 \mathrm{nM}$ to $52 \pm 2 \mathrm{nM}(n=66)$ by caffeine treatment of control neurons and from $49 \pm 2 \mathrm{nM}$ to $75 \pm 4 \mathrm{nM}(n-81)$ by caffeine treatment of IL-6 treated neurons. Dantrolene treatment did not consistently change resting calcium levels.

\section{Discussion}

In this study an enhanced intracellular calcium response to NMDA stimulation during neuronal development was observed 

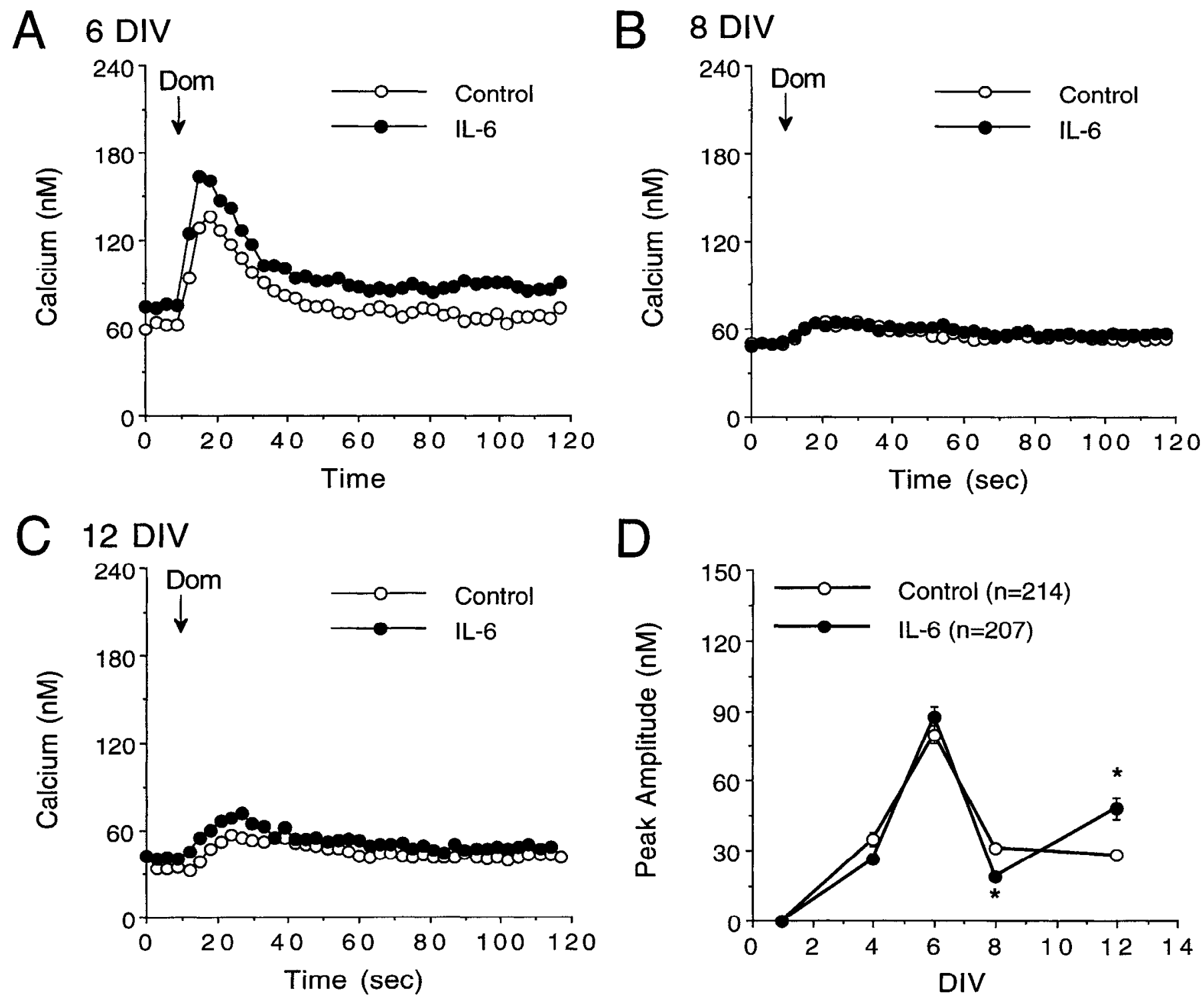

Figure 5. Intracellular calcium signals evoked in cultured cerebellar granule neurons by domoate during neuronal development. $A-C$ show representative recordings of intracellular calcium signals evoked by brief (1 sec) application of domoate (applied at the arrow) from a micropipette in both control (open circle) and IL-6 treated neurons (solid circle) during development. $D$ shows the time-dependent change of intracellular calcium response to domoate during cerebellar neuronal development. Each data point is an average (mean \pm SEM) for cells measured within a particular age group for control neurons (open circle) and IL-6 treated neurons (solid circle). Data points marked with a star indicate a significant $(p<0.05$ ) difference between control and IL- 6 treated neurons. $n$ is the number of cells studied. IL- 6 treatment did not consistently altered the response to domoate.

in cultured rat granule neurons chronically treated with IL-6. In addition, the developmental pattern of NMDA responsivity of the granule neurons was altered by IL- 6 and resting calcium levels were increased. IL-6 treatment did not significantly enhance the intracellular calcium responses to domoate stimulation of kainate receptors or $\mathrm{K}^{+}$-induced membrane depolarization and did not change the developmental profile for these stimulants. These results suggest that early exposure of granule neurons to IL-6 can alter neuronal function and development by selectively increasing the calcium response to NMDA.

The effects of IL-6 on the developing granule neurons required chronic exposure. Acute IL-6 did not reproduce the change in resting intracellular calcium levels or alter the calcium response to NMDA observed with chronic II -6 treatment. Thus, IL-6 appears to exert its effects through a slow regulatory pro- cess such as receptor expression rather than by fast effects such as the changes in enzyme activities.

Activation of NMDA receptors increases intracellular calcium via several pathways: (1) calcium influx through receptor-gated channels, (2) calcium influx through voltage-gated calcium channels activated by membrane depolarization, and (3) release of calcium from intracellular calcium stores. Therefore IL-6 treatment could increase the response to NMDA by altering one or more of these pathways. Domoate and $\mathrm{K}^{+}$depolarization increase intracellular calcium primarily by influx through voltagesensitive calcium channels due to membrane depolarization and release of calcium from intracellular stores, two of the same mechanisms involved in the calcium response to NMDA. The lack of effect of IL- 6 on the response to domoate and $\mathrm{K}^{+}$depolarization would appear to eliminate these common mecha- 

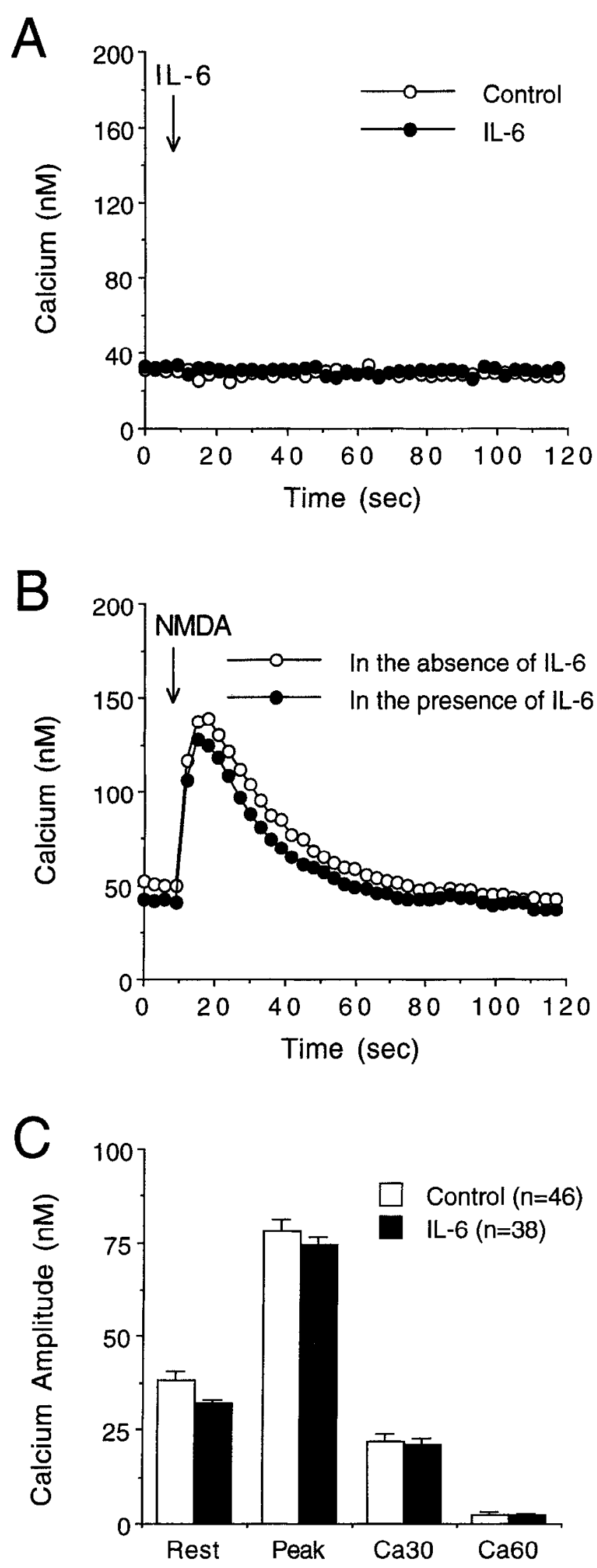

Figure 6. The acute effects of IL-6 on cultured cerehellar granule neurons. Data displayed in $A$ and $B$ are from representative cells. $A$ shows the intracellular calcium responses to IL-6 (applied at the arrow) stimulation in both control (open circle) and IL-6 treated neurons (solid circle) at 5 DIV. $B$ shows the intracellular calcium response to NMDA nisms as sites of IL-6 action. However, further studies with selective calcium channel antagonists and other pharmacological agents will be required before definitive statements can be made.

Lowering extracellular calcium reduced the response to NMDA to a larger extent in IL-6 treated neurons than in control neurons, especially at the older culture ages studied ( 8 and 12 DIV). The greater dependence on extracellular calcium in the IL-6 treated neurons could reflect greater calcium influx and/or an enhanced coupling between influx and release such that larger release occurs in the IL-6 treated neurons, although the influx signal is the same as in control. Studies with caffeine, dantrolene and DTBHQ indicate that release from stores is greater in the IL-6 treated neurons compared to control neurons. Because IL-6 did not alter the responses to domoate and $\mathrm{K}^{+}$depolarization, it is unlikely that IL-6's effects on the NMDA response are primarily due to an IL-6 induced change in calcium influx via voltage-sensitive calcium channels. Increased calcium influx through NMDA-gated channels may be involved, due to an increase in the numbers of NMDA receptors or an increase in the permeability of the receptors to calcium. The subunit composition of the NMDA receptors in granule neurons is known to change during development (Pujic et al., 1993) and could be influenced by IL- 6 treatment. Studies are in progress to address this issue.

Results from studies with various pharmacological agents that alter intracellular stores (e.g., caffeine) showed that release from intracellular stores also plays a prominent role in the enhanced response to NMDA in the IL-6 treated neurons. Others have shown that intracellular stores contribute to the calcium signal induced by NMDA in granule (Simpson et al., 1993) and other neuronal types (Segal and Manor, 1992); however, the effects on IL- 6 on this response parameter has not been previously investigated. The enhanced release from stores could be triggered by enhanced calcium influx via NMDA receptor-gated channels in IL-6 treated neurons. Alternatively, the larger calcium response to NMDA in the IL-6 treated neurons could reflect a larger membranc depolarization, which would activate morc voltage-sensitive calcium channels resulting in increased calcium influx via those channels and, consequently, greater release from intracellular calcium stores. The number or permeability of the voltage-sensitive calcium channels could be altered by IL- 6 treatment as well. However, such an effect would be expected to alter the calcium response to domoate and $\mathrm{K}^{+}$depolarization, which was not observed. Studies with selective calcium channel blockers are in progress to address these issues. Granule neurons are known to express at least four calcium channel types, $\mathrm{L}, \mathrm{N}$, P, and Q (Forti et al., 1994). The effects of IL-6 on the response to NMDA could also reflect a unique spatial relationship between the NMDA receptors and release channels for intracellular stores. Calcium channels and release channels for intracellular stores may not exhibit a similar relationship, thus explaining the lack of effect of IL- 6 on $\mathrm{K}^{+}$depolarization. Moreover, calcium release from overlapping, but nonidentical, intracellular calcium pools could contribute to the differences between NMDA stim-

\section{$\leftarrow$}

stimulation (applied at the arrow) in the presence of IL-6 (solid circle IL-6 was also included in the micropipette), and in the absence of IL- 6 (open circle) in granule neurons at 5 DIV. $C$ displays mean values of resting calcium (Rest), peak calcium amplitude (Peak), calcium amplitude $30 \mathrm{sec}$ after stimulation $(\mathrm{Ca} 30)$, and $60 \mathrm{sec}$ after stimulation $(\mathrm{Ca} 6 \mathrm{O})$. The resting levels were subtracted from amplitude measurements. $n$ is the number of cells studied. Acute treatment of IL-6 did not alter intracellular calcium level or the response to NMDA. 

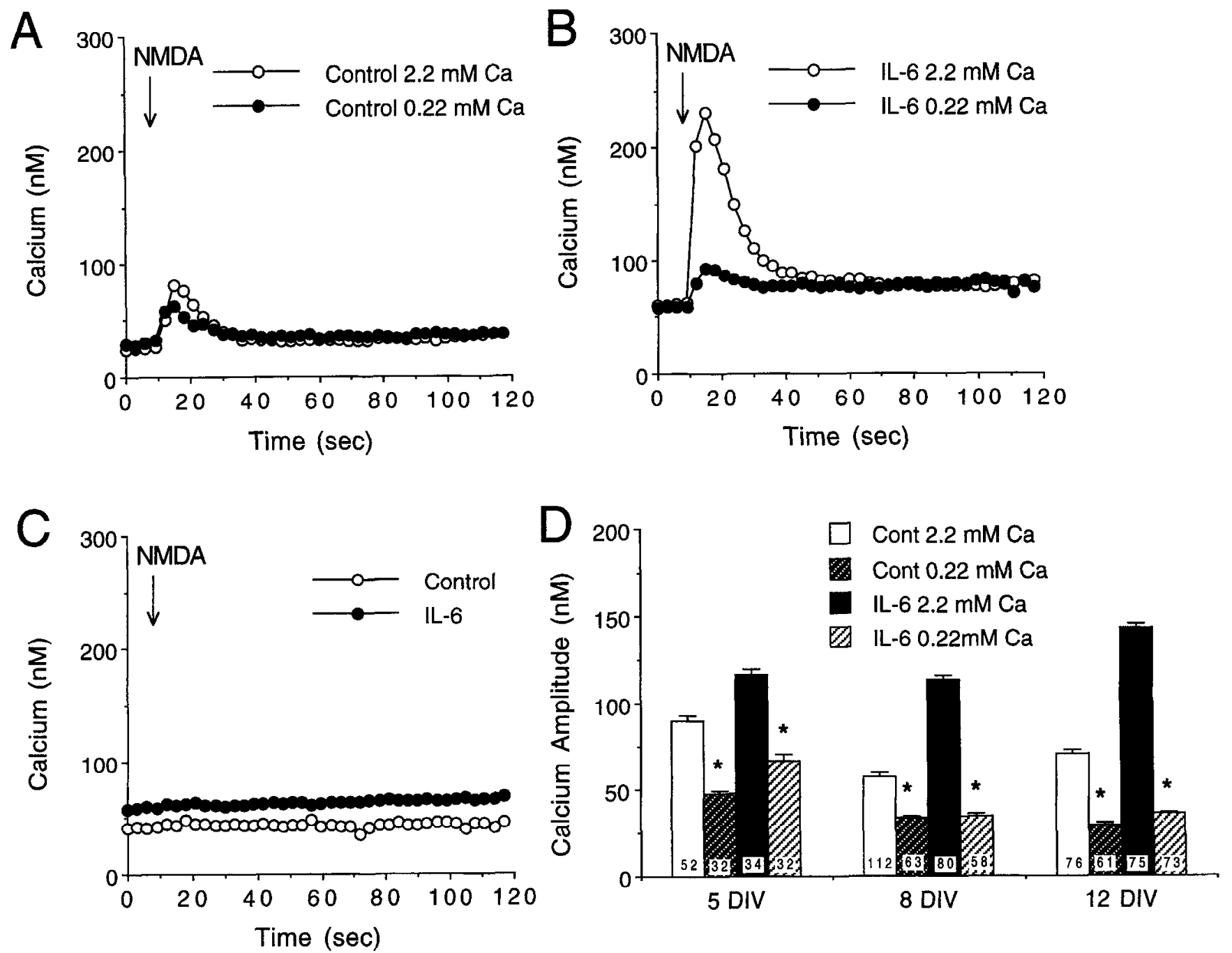

Figure 7. Influence of extracellular calcium on NMDA-induced intracellular calcium responses of cerebellar granule neurons in control and IL-6 treated neurons at different culture ages. Representative recordings are shown in $A-C$ for neurons at 8 DIV. $A$ and $B$ show the effects of lowering extracellular calcium from $2.2 \mathrm{mM}$ (open circle) to $0.22 \mathrm{~mm}$ (solid circle) in both control and IL-6 treated granule neurons, respectively. The NMDA-induced intracellular calcium responses were eliminated in both control (open circle) and IL-6 treated neurons (solid circle) when EGTA titration was used to reduced the extracellular calcium to a nominally calcium- free level $(C)$. $D$ displays mean values of peak calcium amplitude at different extracellular calcium concentration in both control and IL-6 treated neurons during development. Numbers in the histogram represent the number of cells studied. The responses to NMDA was more dependent on extracellular calcium in IL-6 treated neurons as compared to controls at the culture ages.

ulation and $\mathrm{K}^{+}$depolarization (Simpson et al., 1993). Further studies will be necessary for a more complete understanding of the mechanisms underlying IL-6 actions on the calcium signals to NMDA.

During neuronal development the NMDA receptor responses in CNS have been reported to initially increase with age and then decline to adult levels in hippocampal neurons (McDonald et al., 1990a), the visual system (Iwakiri and Komatsu, 1993) and granule neurons of the cerebellum (Farrant et al., 1994). In our studies the ability of NMDA to induce an intracellular calcium response in cultured rat cerebellar granule neurons gradually increased to a peak at postnatal 6 DIV and then declined in magnitude, consistent with the developmental pattern observed for NMDA responses recorded electrophysiologically in granule neurons in slices obtained from postnatal animals (Farrant ct al., 1994). This developmental pattern was also observed for intracellular calcium responses to stimulations of control granule neurons with domoate, but not for $\mathrm{K}^{+}$-induced membrane depolarization. After $6 \mathrm{DIV}$, the response to $\mathrm{K}^{+}$depolarization remained constant at an elevated level, suggesting that the net calcium signal resulting from influx through the voltagesensitive calcium channels and release from stores remains relatively constant during neuronal development. Therefore, the decline in the NMDA and domoate induced calcium signals in control neurons during neuronal development may signify a developmental reduction in the number or the permeability to calcium of the NMDA and kainate receptors. In IL-6 treated neurons, the calcium responses to NMDA did not show this decline and remained elevated during development. These results suggest that early exposure of rat granule neurons to cytokines may alter the developmental expression of NMDA receptors or associated calcium signaling components in the granule neurons.

The current results showing that chronic IL-6 induces an enhanced intracellular calcium responses to NMDA in developing 


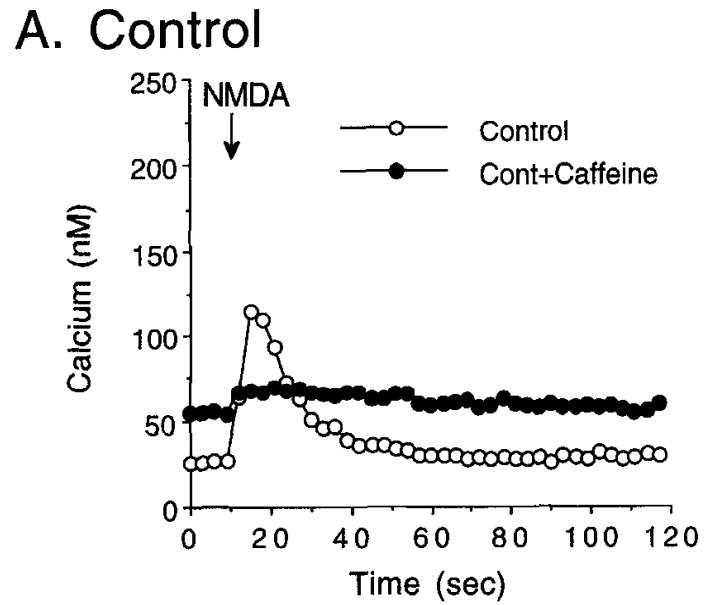

B. IL-6
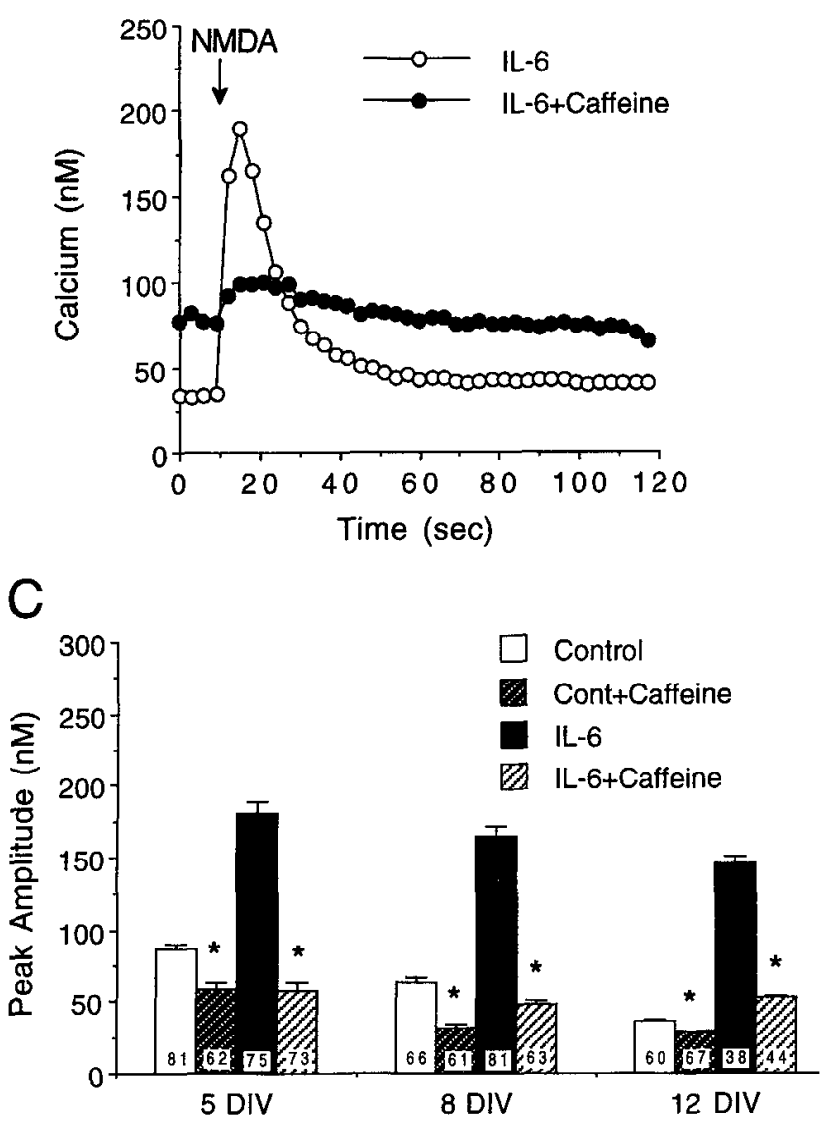

Figure 8. Influence of caffeine on NMDA-induced intracellular calcium responses of cerebellar granule neurons in control and IL-6 treated neurons at different ages of culture. Representative recordings are shown in $A$ and $B$ for neurons at 8 DIV. Caffeine (solid circle) reduced the response to NMDA in both control $(A)$ and IL-6 treated neurons $(B)$. However, the effect was more pronounced in the IL-6 treated neurons. The mean values are displayed in $C$. Numbers in the histogram represent the number of cells studied.

rat granule neurons complements the previous study reported by Holliday et al. (1995). In their study, chronic IL-6 treatment of cultured rat granule neurons enhanced the calcium response to glutamate stimulation at older culture ages (7 and 8 DIV), as was observed for NMDA stimulation in the current study, but depressed the response to glutamate at younger culture ages ( 4

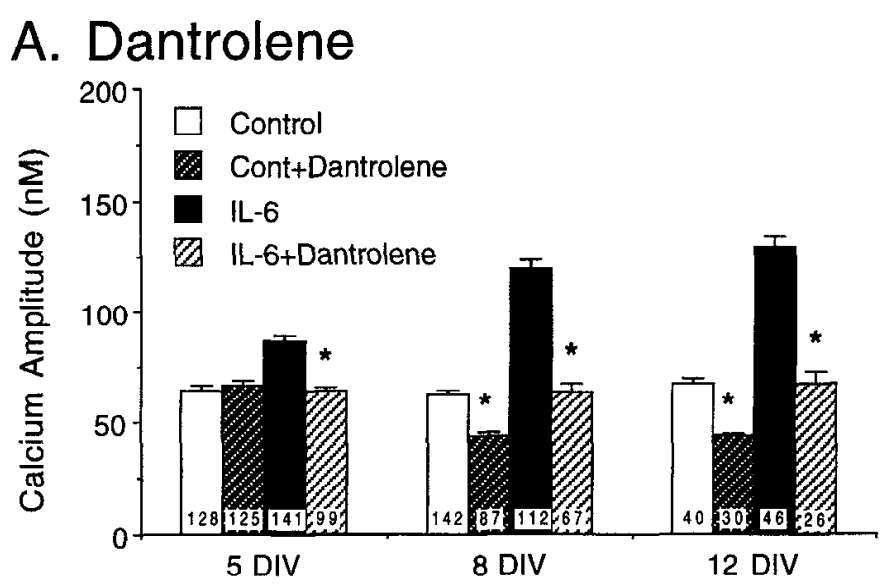

B. DTBHQ

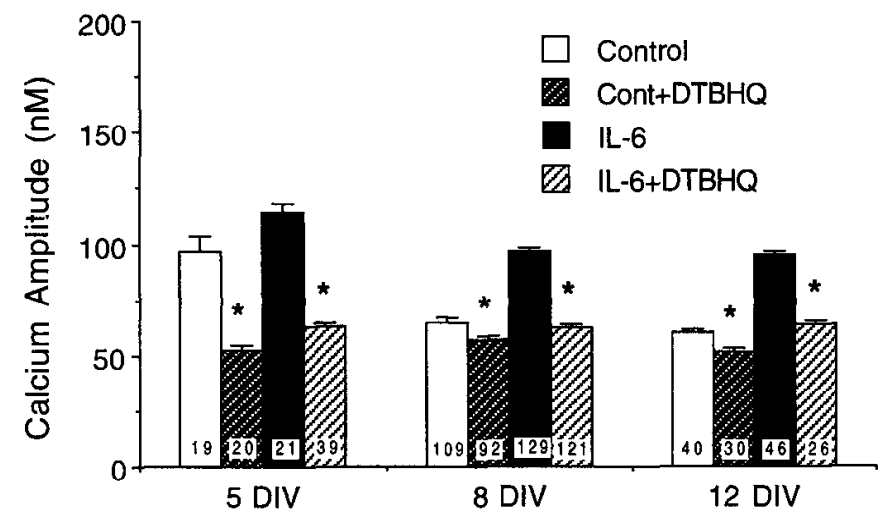

Figure 9. Influence of dantrolene and DTBHQ on NMDA-induced intracellular calcium responses of cerebellar granule neurons in control and IL- 6 treated neurons during neuron development. Dantrolene reduced the calcium responses to NMD $\Lambda$ stimulation only in IL- 6 treated neurons at 5 DIV and in both control and IL- 6 treated neurons at 8 and 12 DIV $(A)$. DTBHQ reduced the calcium response to NMDA stimulation in both control and IL-6 treated neurons during neuronal development, however in the older cultures the effects were pronounced in the IL-6 treated neurons $(B)$. Numbers in the histogram represent the number of cells studied.

and 5 DIV), a time when an enhanced response to NMDA was observed in our current study. In addition, in the studies of Holliday et al. (1995), the response to $\mathrm{K}^{+}$depolarization was enhanced by chronic IL- 6 treatment, whereas in the current study no effect was observed. Several factors could account for these differences: (1) In the current study the intracellular calcium responses to activation of NMDA receptors was examined, whereas in the studies of Holliday et al. (1995) stimulation with glutamatc was used, which would activate multiple subtypes of glutamate receptors, NMDA, AMPA, kainate and metabotropic receptors; (2) In the current study $8 \mathrm{~d}$ postnatal rats were used as a source of granule neurons, whereas 6-7 d postnatal rats were used in the studies of Holliday et al. (1995); (3) The granule neuron cultures used by Holliday et al. (1995) contained almost exclusively granule neurons, which were separated from other cell types by gravity centrifugation. Granule neurons are known to express messenger RNA for IL-6 receptors (Schobitz et al., 1993), and thus the effects of IL- 6 in these cultures are likely to result from direct actions of IL-6 on the granule neu- 
rons. The granule neuron cultures used in the current study were not subjected to this isolation procedure and thus other cell types, such as astrocytes and microglia, were present in relatively small numbers (FUDR treatment was used to restrict their numbers). These cell types can respond to and secrete cytokines or other factors which could then exert additional effects on the granule neurons. These differences raise interesting questions with respect to the influence of maturation and other cell types on the sensitivity and response of granule neurons to IL-6 treatment. Further studies will pursue these issues.

NMDA receptors are known to play an important role in development (McDonald et al., 1990a,b), synaptic plasticity (Kleinschmidt et al., 1987; McCabe and Horn, 1988), and the generation of long-term potentiation (Bliss and Collingridge, 1993) and also in the pathological processes accompanying some neurological diseases in which the excessive calcium influx via NMDA-gated calcium channels and voltage-sensitive calcium channels might contribute to the subsequent neuronal injury (Greenamyre and Young, 1989; Choi, 1992; Lipton, 1992). In addition, NMDA receptors have been proposed to be involved in neurotoxicity caused by viral proteins produced in HIV infection, in which the neurotoxicity could be prevented by cotreatment with an antagonist to NMDA (Lipton et al., 1991) or calcium channel blocker (Dreyer et al., 1990; Lipton, 1992). The current demonstration of the enhancement of intracellular calcium signaling in response to NMDA stimulation in IL-6 treated neurons thus could have important functional implications under conditions of elevated IL-6 levels. Studies in transgenic mice indicate that overexpression of IL-6 can result in significant cerebellar damage (Campbell et al., 1993). Although IL-6 toxicity was not observed in the current study, the functional alterations at cellular level during neuronal development could lead to calcium toxicity or excitotoxicity, which could be a contributing factor in the neuronal damage observed in vivo.

Cytokines are known to influence neuronal development, either by directly acting through their own receptors or by activating neuronal growth factor receptors (Kishimoto et al., 1992). Thus, alterations in the normal cytokine levels in the brain are likely to affect CNS neuronal development and function. The mechanisms through which elevated cytokines affect neurons and their development are only beginning to be understood. Our studies of cultured granule neurons examining the relationship between NMDA receptor, cytokines and neuronal development demonstrate the potential for cytokines to alter this important aspect of neuronal function in the developing nervous system, either as a component of the neuronal developmental process or as a contributing factor in the pathologic state.

\section{References}

Belman AL (1994) HIV-1-associated CNS disease in infant and children. In: HIV, AIDS, and the brain (Price RW, Perry SW, eds), pp 289-310. New York: Raven.

Bliss TVP, Collingridge GL (1993) A synaptic model of memory: longterm potentiation in the hippocampus. Nature 361:31-39.

Brenneman DE, McCune SK, Gozes I (1990) Acquired immune deficiency syndrome and the developing nervous system. Int Rev Neurobiol 32:305-353.

Campbell IL, Abraham CR, Masliah E, Kemper P, Inglis JD, Oldstone MB, Mucke L (1993) Neurologic disease induced in transgenic mice by cerebral overexpression of interleukin 6. Proc Natl Acad Sci USA 90:10061-10065.

Charles AC, Dirksen ER, Merrill JE, Sanderson MJ (1993) Mechanisms of intercellular calcium signaling in glial cells studied with dantrolene and thapsigargin. Glia 7:134 145 .

Choi DW (1992) Excitotoxic cell death. J Neurobiol 23:1261-1276.
Dreyer EB, Kaiser PK, Offermann JT, Lipton SA (1990) HIV-1 coat protcin neurotoxicity prevented by calcium channel antagonists. Science 248:364-367.

Farrant M, Feldmeyer D, Takahashi T, Cull-C SG (1994) NMDA-receptor channel diversity in the developing cerebellum. Nature 368: 335-339.

Forti L, Tottene A, Moretti A, Pietrobon D (1994) Three novel types of voltage-dependent calcium channels in rat cerebellar neurons. J Neurosci 14:5243-5256.

Frei K, Malipiero UV, Leist TP, Zinkernagel RM, Schwab MF, Fontana A (1989) On the cellular source and function of interleukin 6 produced in the central nervous system in viral diseases. Eur J Immunol 19:689-694.

Gallo P, Laverda AM, De Rossi A, Pagni S, Del Mistro A, Cago P, Piccinno MG, Plebani A, Tavolato B, Bianchi CL (1991) Immunological markers in the cerebrospinal fluid of HIV-1-infected children. Acta Pædiator Scand 80:659- 666.

Greenamyre JT, Young AB (1989) Excitatory amino acids and Alzheimer's disease. Neurobiol Aging 10:593-602.

Griffin WST, Stanley IC, Ling C, White I, MacLeod V, Perrot LJ, White CL III, Araoz C (1989) Brain interleukin 1 and S-100 immunoreactivity are elevated in down syndrome and Alzheimer disease. Proc Natl Acad Sci USA 86:7611-7615.

Grynkiewicz G, Poenie M, Tsien RY (1985) A new generation of $\mathrm{Ca}^{2+}$ indicators with greatly improved fluorescence properties. J Biol Chem 260:3440.

Hirano T (1992) The biology of interleukin-6. Chem Immunol 51:153180.

Hirohata S, Miyamoto T (1990) Elevated levels of interleukin-6 in cerebrospinal fluid from patients with systemic lupus erythematosus and central nervous system involvement. Arthritis Rheumatism 33: 644-649.

Hockberger PE, Tseng HY, Connor JA (1994) Immunocytochemical and electrophysiological differentiation of rat cerebellar granule cells in explant cultures. J Neurosei 7:1370-1383.

Holliday J, Gruol DL (1993) Cytokine stimulation increases intracellular calcium and alters the response to quisqualate in cultured cortical astrocytcs. Brain Res 621:233-241.

Holliday J, Adams RJ, Sejnowski TJ, Spitzer NC (1991) Calciuminduced releases of calcium regulates differentiation of cultured spinal neurons. Neuron 7:787-796.

Holliday J, Parsons KL, Lee SY, Curry JG, Gruol DL (1995) Cerebellar granule neurons develop elevated calcium responses when treated with interleukin-6 in culture. Brain Res 673:141-148.

Ip NY, Nye SH, Boulton TG, Davis S, Taga T, Li Y, Birren SJ, Yasukawa K, Kishimoto T, Anderson DI, Stahl N, Yancopoulos GD (1992) CNTF and LIF act on neuronal cells via shared signaling pathways that involve the IL- 6 signal transducing receptor component gp 130. Cell 89:1121-1132.

Iwakiri M, Komatsu Y (1993) Postnatal development of NMDA receptor-mediated synaptic transmission in cat visual cortex. Brain Res Dev Brain Res 74:89-97.

Kass GE, Duddy SK, Moore GA, Orrenius S (1989) 2,5-Di-(tert-butyl)1,4-benzohydroquinone rapidly elevates cytosolic $\mathrm{Ca}^{2+}$ by mobilizing the inositol 1,4,5- trisphosphate-sensitive $\mathrm{Ca}^{2+}$ pool. J Biol Chem 264:15192-15198.

Kishimoto T, Akira S, Taga T (1992) Interleukin-6 and its receptor: a paradigm for cytokines. Science 258:593-597.

Kleinschmidt A, Bear MF, Singer W (1987) Blockade of "NMDA" receptors disrupts experience-dependent plasticity of kitten striate cortex. Science 238:355-358.

Komuro H, Rakic P (1993) Modulation of neuronal migration by NMDA receptors. Science 260:95-97.

Laurenzi MA, Siden A, Persson MAA, Norkrans G, Hagberg L, Chiodi F (1990) Cerebrospinal fluid interleukin-6 activity in HIV infection and inflammatory and noninflammatory diseases of the nervous system. Clin Immunol Immunopathol 57:233-241.

Lipton SA (1992) Models of neuronal injury in AIDS: another role for the NMDA receptor? Trends Neurosci 15:75-79.

Lipton SA, Sucher NJ, Kaiser PK, Dreyer EB (1991) Synergistic effects of HIV coat protein and NMDA receptor-mediated neurotoxicity. Neuron 7:111-118.

McCabe BJ, Horn G (1988) Learning and memory: regional changes in $N$-methyl-D-aspartate receptors in the chick brain aftcr imprinting. Proc Natl Acad Sci USA 85:2849-2853. 
McDonald JW, Johnston MV (1990b) Physiological and pathophysiological roles of excitatory amino acids during central nervous system development. Brain Res 15:41-70.

McDonald JW, Johnston MV, Young AB (1990a) Differential ontogenic development of three receptors comprising the NMDA receptor/channel complex in the rat hippocampus. Exp Neurol 110:237247.

Miller RJ (1991) The control of neuronal calcium homeostasis. Prog Neurobiol 37:255-285.

Monaghan DT, Bridges RJ, Cotman CW (1989) The excitatory amino acid receptors: their classes, pharmacology, and distinct properties in the function of the central nervous system. Annu Rev Pharmacol Toxicol 29:365-402.

Monyer H, Burnashev N, Laurie DJ, Sakmann B, Seeburg PH (1994) Developmental and regional expression in the rat brain and functional properties of four NMDA receptors. Neuron 12:529-540.

Perrella O, Carrieri PB, Guarnaccia D, Soscia M (1992) Cerebrospina fluid cytokines in AIDS dementia complex. J Neurol 239:387-388.

Pujic Z, Matsumoto I, Wilce PA (1993) Expression of the gene coding for the NR1 subunit of the NMDA receptor during rat brain development. Neurosci I ett 162:67-70.

Sawada M, Itoh Y, Suzumura A, Marunouchi T (1993) Expression of cytokine receptors in cultured neuronal and glial cells. Neurosci Lett 160:131-134.

Schobitz B, Voorhuis DAM, De Kloet ER (1992) Localization of interleukin $6 \mathrm{mRNA}$ and interleukin 6 receptor $\mathrm{mRNA}$ in rat brain Neurosci Lett 136:189-192.

Schobitz B, De Kloet ER, Sutanto W, Holsboer F (1993) Cellular lo- calization of interleukin $6 \mathrm{mRNA}$ and interleukin 6 receptor mRNA in rat brain. Eur J Neurosci 5:1426-1435.

Segal M, Manor D (1992) Confocal microscopic imaging of $\left[\mathrm{Ca}^{2+}\right]_{i}$ in cultured rat hippocampal neurons following exposure to $\mathrm{N}$-methyl-Daspartate. J Physiol (Lond) 448:655-676.

Simpson PB, Challiss RA, Nahorski SR (1993) Involvement of intracellular stores in the $\mathrm{Ca}^{2+}$ responses to $N$-methyl-D- aspartate and depolarization in cerebellar granule cells. J Neurochem 61:760- 763 .

Stahl N, Boulton TG, Farruggella T, Ip NY, Davis S, Witthuhn BA, Quelle FW, Silvennoinen O, Barbieri G, Pellegrini S (1994) Association and activation of Jak-Tyk kinases by CNTF-LIF-OSM-IL-6 beta receptor components. Science 263:92-95.

Taga T, Hibi M, Murakami M, Saito M. Yawata H, Narazaki M. Hirata Y, Sugita T, Yasukawa K, Hirano T (1992) Interleukin-6 receptor and signals. Chem Immunol 51:181-204.

Traynelis SF, Cull-Candy SG (1991) Pharmacological properties and $\mathrm{H}^{+}$sensitivity of excitatory amino acid receptor channels in rat cerebellar granule neurones. J Physiol (Lond) 433:727-763.

Trenkner E (1991) Cerebellar cells in culture. In: Culturing nerve cells (Banker G, Goslin K, eds), pp 283-307. Cambridge, MA: MIT Press.

Tsien RW, Tsien RY (1990) Calcium channels, stores and oscillations. Annu Rev Cell Biol 6:715-760.

Tyor WR, Glass JD, Griffin JW, Becker PS, McArthur JC, Bezman L, Griffin DE (1992) Cytokine expression in the brain during the acquired immunodeficiency syndrome. Ann Neurol 31:349-360.

Waage A, Halstensen A, Shalbaby R, Brandtzaeg P, Kierulf P, Espevik $T$ (1989) Local production of tumor necrosis factor a, interleukin 1, and interleukin 6 in meningococcal meningitis. Relation to the inflammatory response. J Exp Med 170:1859-1867. 